\title{
CENÁRIOS AMBIENTAIS E O INCENTIVO À PROTEÇÃO DE ÁREAS DE PRESERVAÇÃO PERMANENTE NA MICROBACIA DO RIO FAGUNDES, PARAÍBA DO SUL/RJ
}

\author{
ENVIRONMENTAL SCENARIOS AND THE INCENTIVE TO PROTECT PERMANENT PRESERVATION AREAS IN THE \\ MICROBACIA DO RIO FAGUNDES, PARAÍBA DO SUL/RJ
}

\begin{abstract}
RESUMO
Para incentivar os agricultores a preservar e/ou restaurar a vegetação nativa como previsto na Lei 12.651/2012, um programa de desenvolvimento rural sustentável do Rio de Janeiro investe na proteção e recuperação de Áreas de Preservação Permanente, especialmente as de nascente. $O$ objetivo deste trabalho, relacionado a este programa, é construir cenários ambientais que subsidiem o planejamento e a gestão de APPs. A metodologia é a quantificação das classes de cobertura da terra: "Floresta", "Não Floresta", "Água" e "Não Classificada", usando geotecnologias em duas cenas comparativas, 2011 e 2016, e um cenário futuro, 2046. Foram utilizados o programa ArcGis 10.3 para processamento de imagem digital, os sensores Landsat 5 TM e Landsat 8 OLI e o programa Idrisi Selva 17.0/Land Change Modeler para a geração de modelos preditivos e análise comparativa. Os resultados indicam que, entre 2011 e 2016, houve um aumento de 160,4 hectares da classe "Não Floresta" em relação à "Floresta": a classe "Floresta" diminuiu 7,4\%, enquanto a classe "Não Floresta" aumentou 5,33\%. Para o cenário futuro 2046, o modelo probabilístico markoviano apresenta 52\% de chance de conversão da classe "Floresta" em "Não Floresta", portanto, há uma predição de cenário futuro tendencial pessimista de desmatamento. Recomendase o monitoramento da microbacia conjugado a mudanças na cobertura da terra e a ações de preservação de "Floresta".
\end{abstract}

Palavras-chave: Mudança de cobertura de terra. Cenários ambientais. Land Change Modeler. Microbacias Hidrográficas. Áreas protegidas.

\begin{abstract}
To encourage farmers to preserve and/or restore native vegetation as envisaged in Law $12,651 / 2012$, a sustainable rural development program in Rio de Janeiro invests in the protection and recovery of permanent preservation areas, especially in the spring. Related to the program, the objective of this work is to construct environmental scenarios in the Fagundes River Basin in Paraíba do Sul/RJ, which will subsidize the planning and management of PPAs. The methodology is the quantification of land cover classes, "Forest", "Non Forest", "Water" and "Unclassified" using geotechnologies in two comparative scenarios, 2011 and 2016 and a future scenario, 2046. The program was used ArcGis 10.3 for digital image processing, the Landsat 5TM and Landsat $8 \mathrm{OLI}$ sensors and the Idrisi Selva 17.0/Land Change Modeler program for the generation of predictive models and comparative analysis. The results indicate that, between 2011 and 2016, there was an increase of 160.4 hectares of the "No Forest" class on the "Forest" class: the "Forest" class decreased by $7.4 \%$, while the "No Forest" class increased 5.33\%. For the future scenario 2046, the Markovian probabilistic model presents a $52 \%$ chance of converting from the "Forest" class to "No Forest", therefore, there is a prediction of a pessimistic future trend of deforestation. It is recommended the monitoring of the watershed related to changes in the land cover and actions of preservation of "Forest".
\end{abstract}

Keywords: Land cover change. Environmental scenarios. Land Change Modeler. Waterhed. Protected areas.

\author{
Cintia de Andrade Corrêa \\ Leandro Andrei Beser de Deus \\ (D) Nadja Maria Castilho da Costa \\ ${ }^{\text {a }}$ Universidade do Estado do Rio de \\ Janeiro (UERJ)
}

DOI: 10.12957/geouerj.2020.30728

\section{Correpondência:}

leandroandrei@yahoo.com.br

Recebido em: 08 out. 2017

Aceito em: 06 out.2020 


\section{INTRODUÇÃO}

A intervenção humana em áreas protegidas gera grandes impactos ambientais resultantes, em muitos casos, da retirada da cobertura vegetal original e sua substituição para usos agropecuários (CASTRO; GOMES, 2001, p. 21). Para incentivar o produtor rural a preservar as Áreas de Preservação Permanente -APPs e a recompor a vegetação nativa e as nascentes, foi criado o programa fluminense de desenvolvimento rural sustentável, o "Rio Rural nascente protegida" (EMATER, 2016, s/p.), em conformidade com a Lei 12.651/2012 (BRASIL, 2012).

Segundo a Lei 12.651/2012 (BRASIL, 2012, s/p), artigo 3 , entende-se por APP:

(...) área protegida, coberta ou não por vegetação nativa, com a função ambiental de preservar os recursos hídricos, a paisagem, a estabilidade geológica e a biodiversidade, facilitar o fluxo gênico de fauna e flora, proteger o solo e assegurar o bem-estar das populações humanas.

As Áreas de Preservação Permanente têm como função preservar o solo e os recursos hídricos e assegurar a qualidade de vida das populações humanas e outras, com suas categorias colocadas pelo artigo 4으, incisos I a XI (BRASIL, 2012, s/p):

\footnotetext{
I - faixas marginais de qualquer curso d'água natural perene e intermitente, excluídos os efêmeros (...); II - entorno dos lagos e lagoas naturais (...); III - entorno dos reservatórios d'água artificiais (...); IV entorno das nascentes e dos olhos d'água perenes (...); $\mathrm{V}$ - encostas com declividade superior a $45^{\circ}$; $\mathrm{VI}$ - restingas; VII - manguezais; VIII - bordas dos tabuleiros ou chapadas; IX - topo de morros, montes, montanhas e serras (...); X - áreas em altitude superior a 1.800 metros; XI - veredas (...)
}

Segundo Garay e Becker (2006, p. 45), "as APPs foram instituídas por representarem uma clara tentativa de conter avanços sobre a floresta sob a forma de grilagem de terras", sendo o maior conflito destas áreas relacionado à sua ocupação e ao "ônus de proteção" dado aos proprietários de terras com mesmos critérios de localização, delimitação, função e categorias em áreas urbanas ou rurais e em todo o território nacional.

Neste sentido, de acordo com a realidade das APPs rurais relacionada à preservação e à necessidade de proteção para geração de água, proteção do solo e florestas, objetiva-se aqui construir cenários ambientais com ênfase em modelos preditivos de simulação, uma metodologia proposta por Beser de Deus (2013), aplicada na Microbacia Rio do Fagundes - MBRF, no município de Paraíba do Sul/RJ, como proposta de um sistema de apoio ao planejamento ambiental (SANTOS, 2004) e à decisão de práticas de desenvolvimento rural sustentável por meio do programa Rio Rural (SEAPEC, 2016).

Cenários ambientais são interpretações de momentos em uma paisagem dentro de uma escala temporal visando à compreensão da dinâmica da área e problemas ambientais consequentes (SANTOS, 2004, p. 50). São instrumentos fundamentais para o planejamento ambiental. Para Beser de Deus (2013, p. 31), "trata-se da configuração de um sistema ou da situação que se deseja conhecer, sempre vinculada a um período de tempo". Cenários podem utilizar, conjuntamente, modelos preditivos ou de simulação associados a narrativas contextualizadas. Um dos cenários mais utilizados é o tendencial. Seus modelos de previsão apenas extrapolam condições atuais, com base em análises 
estatísticas e/ou tendências históricas, mantendo suas probabilidades ou alterando-as por meio de pequenos ajustes (BESER DE DEUS, 2013).

Para tal construção, são tomadas abordagens, tecnologias e recorte espaçotemporal integrados ao planejamento ambiental e ao apoio à decisão. Podem ser utilizadas técnicas de processamento digital de imagens, com destaque para a classificação digital de imagens de sensoriamento remoto, associada à modelagem de mudanças (e/ou de simulação espaçotemporal) com base em cadeias de Markov e em métodos heurísticos avançados, como as redes neurais artificiais (RNAs).

Importantes estudos que envolvem modelos preditivos e cenários futuros de uso e cobertura da terra ou ambientais são desenvolvidos no mundo. Como exemplo de aplicações pode-se citar os estudos de Mishra et al. (2014) na Índia, Cheng e Ding (2016) no Estados Unidos, Khawaldah (2016) na Jordânia. No Brasil, destacam-se os estudos realizados na Amazônia (BESER DE DEUS, 2013), em São Paulo (ZANATA, 2014; PIROLI, 2014) e em Minas Gerais (LUIZ, 2014). No Brasil, o projeto “Cenários para a Amazônia”, um projeto interinstitucional, é referência. Concebido com o objetivo de desenvolver um modelo integrado - "SimAmazonia" simula a complexa interação entre os ecossistemas da Amazônia e avalia o potencial de políticas públicas (SOARES FILHO, 2008). Outros trabalhos, como o de Soares-Filho et al. (2004a, 2004b, 2005), o de Leite et al. (2012) e o de Sartori et al. (2013) revelam a dinâmica de uso e cobertura da terra para o desenvolvimento de cenários ambientais futuros em bacias hidrográficas em decorrência do desenvolvimento do setor agropecuário, porém em detrimento da proteção e preservação ambiental.

Em tais cenários de desmatamento e de degradação da cobertura da terra, as microbacias hidrográficas de uso rural, são exemplos de como a água, considerando as particularidades reservadas às categorias de APPs nestes espaços (por exemplo, das "APPs Hídricas", com sua importância e função ambiental de proteção da água), são consideradas fundamentais e que é necessário para proteger e recuperar as nascentes e os recursos hídricos.

Recentemente têm sido abordados, em importantes estudos em relação a esta questão, o desenvolvimento territorial rural e a ampliação da oferta/geração de água pelo fomento de Programas de Pagamentos por Serviços Ambientais - PSAs. São exemplos o Projeto de Extrema em Minas Gerais, o Projeto Guandu e o Programa Rio Rural no Rio de Janeiro (PAGIOLA et al., 2013).

Rodrigues e De Freitas Leitão-Filho (2000) discutem a capacidade hidrológica das matas ciliares e a capacidade de armazenagem da água em bacias hidrográficas protegidas, por exemplo, da filtragem de sedimentos e do encharcamento do solo, assim como de características florestais, hidrogeomorfológicas e da paisagem da bacia. Portanto, a quantificação da relação entre "Floresta" e "Não Floresta" é essencial para simulações no âmbito de um cenário futuro tendencial da recuperação da quantidade e qualidade da água. 


\section{ÁREA DE ESTUDO}

A área de estudo (Figura 1) é a Microbacia do Rio Fagundes - MBRF, cuja extensão de 2.975,72 hectares (ha) é localizada na zona rural ao sul do município de Paraíba do Sul, divisa com os municípios fluminenses de Paty do Alferes, Areal e Petrópolis, na região centro-sul fluminense, no estado do Rio de Janeiro, Brasil. É uma unidade territorial de planejamento, com coordenadas UTM 685264,75X e 674696,82X; 7536002,00 Y e 7525911,50 Y.

Encontra-se no vale do Rio Paraíba do Sul, ao sopé da serra do Mar, onde se situava uma das mais belas e exuberantes florestas tropicais, a floresta ombrófila de influência de clima úmido com altitudes variam de 500 a 600 metros, em áreas mais planas e adjacentes ao rio principal, e de 900 a 1.000 metros e precipitações médias anuais em torno de 1.730 mm (DANTAS, 2000; INEA, 2016).

Figura 1. Mapa de localização da Microbacia do Rio Fagundes

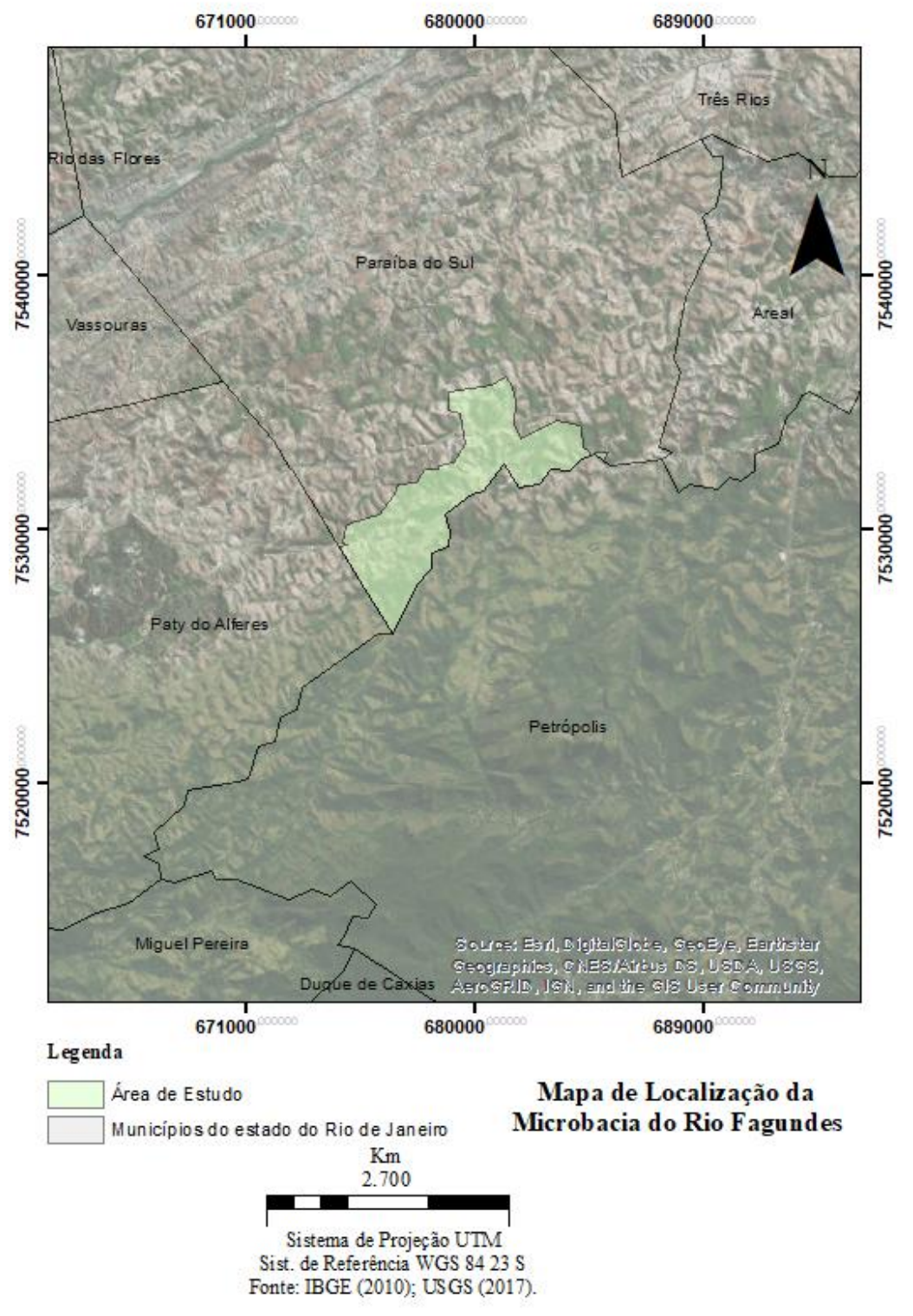


A Microbacia do Rio Fagundes é uma das microbacias de trabalho propostas pelo Programa Rio Rural de Desenvolvimento Rural Sustentável Fluminense de PSA (SEAPEC, 2016; EMATER, 2016). No município de Paraíba do Sul, esta é uma área de uso agropecuário e com intensa degradação devido a diversos ciclos econômicos pelos quais passou a Bacia Hidrográfica do Rio Paraíba do Sul. É também um importante eixo de ocupação e desenvolvimento: a princípio, ocupado pela produção de café; posteriormente, pela atividade pecuária (COOPETEC, 2006).

Esta microbacia é uma importante área para recuperação e ampliação da geração de água, sustentabilidade, redução de assoreamento por produção de sedimentos (proteção do solo) por processos erosivos e redução de inundações. É considerada uma área piloto de ação do programa Rio Rural e uma das mais produtivas (produção de oleícolas) da região centro-sul fluminense, e localizada em uma das bacias hidrográficas mais importantes do Brasil, e seu desenvolvimento rural sustentável e sua produção de água tornam-se extremamente necessários.

\section{METODOLOGIA DO TRABALHO}

\section{Materiais}

Os materiais utilizados para construção dos cenários foram o programa ArcGIS 10.3 (ESRI, 2014), para a estruturação do banco de dados espaçotemporal, construção das cenas pretéritas e atuais, integração das camadas trabalhadas, análises espaçotemporais vetoriais, saídas gráficas e para classificação digital de imagens do satélite Landsat 5 TM e do Landsat 8; e o Idrisi Selva (LABS, 2012), para a construção das cenas futuras e demais análises espaço-temporais.

\section{Compartimentação temporal e elaboração de cenas e cenários}

Para inferir as mudanças ocorridas entre dois momentos estabelecidos no tempo pelo modelo Land Change Modeler (LCM), são necessários dois produtos espacializados no intervalo de tempo analisado. Este compreende o período de que norteará a elaboração de cenários. O período utilizado para aplicação da metodologia de trabalho como um cenário ambiental atual, 1999-2016, foi considerado a partir do Projeto de Lei 1.876/1999, que "dispõe sobre áreas de preservação permanente, reserva legal, exploração florestal e dá outras providências" (revogando a Lei 4.771/1965 e alterando a Lei 9.605/1998) passando pela promulgação da Lei 12.651 em 2012 até o ano de 2016 (BRASIL, 1999). O ano de 2046 foi considerado por se tratar de um período de 30 anos depois, considerado um tempo-resposta. 
Delimitação da Microbacia do Rio Fagundes/área de estudo

A delimitação da MBRF, área de estudo, foi realizada de forma automática, chamada "geração automática de bacias" (ESRI, 2014) com base cartográfica da rede de drenagem e modelo digital de elevação (MDE) gerado a partir de curvas de nível, disponibilizadas gratuitamente em shapefiles pelo INEA (2016). Previamente, foram realizados trabalhos de campo na MBRF com a Emater Paraíba do Sul/RJ.

Aquisição de imagens/elaboração de cenas ambientais

Para a análise das mudanças de cobertura da terra ocorrida entre 2011 e 2016, foram utilizadas imagens raster de resolução espacial de 30 metros por 30 metros, no sistema de coordenadas UTM $23 \mathrm{~S}$ e datum WGS 84.

Foram utilizadas duas imagens orbitais para a elaboração das cenas ambientais para a caracterização e interpretação das principais formas de cobertura da terra: a imagem do sensor Landsat TM 5 com resolução espacial de 30 metros, obtida na data de 12 de julho de 2011, órbita 217 e ponto 075 e composição colorida padrão R (Red) G (Green) B (Blue) e arranjo das bandas 5, 4, 3 (vegetação); e a imagem do sensor Landsat 8 OLI, obtida na data de 25 de julho de 2016, órbita 217 e ponto 075, também com composição colorida padrão RGB para geração de resultados similares para a vegetação e arranjo das bandas 6, 5, 4 (sequência numérica diferente devido à inclusão de duas novas bandas no satélite Landsat Data Continuity Mission - LDMC).

A imagem de 2011, Landsat 5 TM, e a imagem do Landsat 8 foram (re)projetadas para o hemisfério sul com a ferramenta project raster. 0 datum de referência foi WGS 84, folha 23S, coordenadas UTM (Universal transversa de Mercator) para ambas as imagens. As imagens disponibilizadas são ortorretificadas e disponibilizadas gratuitamente pela USGS (2016).

\section{Processamento digital de imagens, classificação da cobertura da terra e construção de cenas}

O cenário presente foi definido como o intervalo entre 2011 e 2016 e o cenário futuro considerado teve como marco temporal o ano de 2046. O tipo de cenário elaborado foi o tendencial, "do tipo extrapolativo, definido do passado, incluindo o presente, para o futuro, podendo ser ou não o cenário mais provável” (BESER DE DEUS, 2013, p. 77).

Em relação à definição das classes para quantificação de cobertura da terra e em atendimento aos objetivos propostos, foram definidas: "Floresta", "Não Floresta" (pastagem e solo exposto foram assim 
classificadas), "Água" e "Não Classificada" (parte da imagem sombreada, com dificuldade de interpretação e agrupamento dos alvos nuvem e sombra) (Figura 2).

Figura 2. Imagens amostrais de cada classe

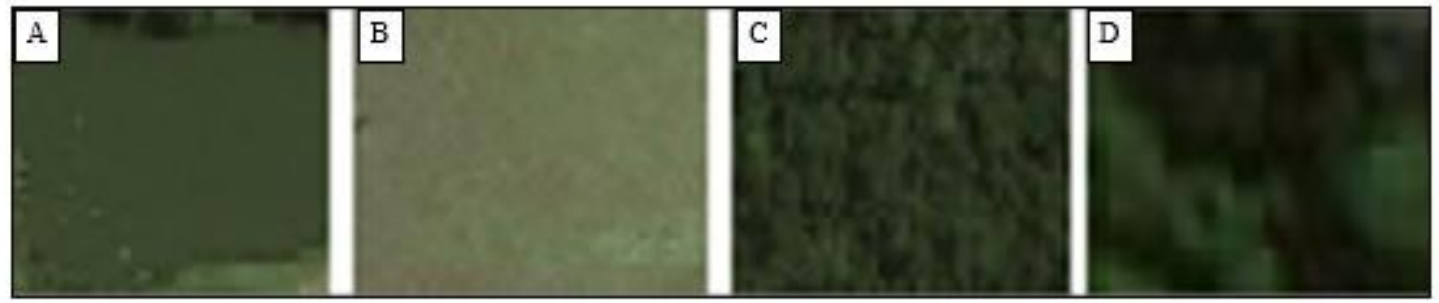

Legenda: (A) Água; (B) Não Floresta; (C) Floresta e (D) Não classificada.

As classes de cobertura da terra foram processadas por uma classificação supervisionada por Máxima Verossimilhança MAXVER (usa a informação espectral de cada pixel na busca por homogeneidade). Esta classificação exige o conhecimento prévio do analista sobre a localização de algumas amostras das classes que serão mapeadas. A utilizada neste trabalho tem o perfil determinista e se baseia no pressuposto de que cada classe espectral pode ser descrita por amostras fornecidas pelo analista (NOVO, 2010). As quatro classes se deram com o uso da ferramenta image classification. A qualidade da imagem do Landsat TM 5 de 2011, no que se refere ao sombreamento e seu envolvimento na classificação, representou um desafio metodológico relacionado à qualidade das imagens para o estudo das APPs.

As classes de cobertura da terra, 2011 e 2016, foram validadas através da distribuição de 50 pontos aleatórios pela ferramenta Create Random Points do ArcGis 10.3, em cada uma das classes. Isso corresponde a um número mínimo de observações para uma boa avaliação estatística da acurácia dos resultados (CONGALTON, 1991). As quantidades distribuídas em cada uma das quatro classes resultaram em um total de 200 pontos. Após a geração dos pontos, utilizou-se a ferramenta Extract Values Points para a atribuição de classe. Para a verificação da realidade, tomou-se como base o Google Earth, séries históricas, com imagens de julho/2011 e julho/2016.

E, por fim, elaborada uma Matriz de Confusão com a obtenção do Índice Kappa e a obtenção da Exatidão Global para as validações da cobertura da terra em 2011 e em 2016. Em 2011 obteve-se um Índice Kappa igual a 0,95 e inferência da Exatidão Global igual a 0,96 (Tabela 1). E em 2016, um Índice Kappa igual a 0,95 e inferência da Exatidão Global igual a 0,96 (Tabela 2). Em ambas as classificações houve um desempenho, classificado segundo Fonseca (2000), muito bom. 
Tabela 1. Matriz de confusão aplicada à classificação da cobertura da Terra da MBRF em 2011

\begin{tabular}{cccccc}
\hline Cobertura - & \multicolumn{5}{c}{ Cobertura - Realidade } \\
Classificação & Floresta & Não Floresta & Água & Não Classificada & Total \\
\hline Floresta & 47 & 3 & 0 & 0 & 50 \\
Não Floresta & 2 & 48 & 0 & 0 & 50 \\
Água & 0 & 2 & 48 & 0 & 50 \\
Não Classificada & 0 & 0 & 0 & 50 & 50 \\
Total & 49 & 51 & 48 & 50 & 200 \\
Exatidão por classe & 94 & 96 & 96 & 100 & - \\
Índice kappa & & & 0,95 & & \\
Índice kappa em & & 95 & \\
porcentagem (\%) & & & 0,96 & \\
Exatidão Global & &
\end{tabular}

Tabela 2. Matriz de confusão aplicada à classificação da cobertura da Terra da MBRF em 2016

\begin{tabular}{cccccc}
\hline Cobertura - & \multicolumn{5}{c}{ Cobertura - Realidade } \\
Classificação & Floresta & Não Floresta & Água & Não Classificada & Total \\
\hline Floresta & 48 & 2 & 0 & 0 & 50 \\
Não Floresta & 3 & 47 & 0 & 0 & 50 \\
Água & 0 & 2 & 48 & 0 & 50 \\
Não Classificada & 0 & 0 & 0 & 50 & 50 \\
Total & 51 & 51 & 48 & 50 & 200 \\
Exatidão por classe & 96 & 94 & 96 & 100 & - \\
Índice kappa & & & 0,95 & & \\
Índice kappa em & & & 95 & & \\
porcentagem (\%) & & & 0,96 & \\
Exatidão Global & &
\end{tabular}

Os resultados da classificação foram chamados de cenas ambientais e serviram de input para a modelagem preditiva e a análise comparativa. Os valores de área (em hectares) das classes de cobertura da terra também foram quantificados, considerando o período presente e a cobertura da terra para as quatro classes propostas.

Os trabalhos de campo realizados foram importantes para a validação dos resultados das classificações.

Inserção da cobertura da terra no LCM para o cenário atual 2011-2016 e cenário fututo no ano de 2046

Os arquivos raster, já classificados como cenas ambientais espacializadas, foram inseridos no modelo Land Change Modeler - LCM for Ecological Sustaintability Project Parameters do programa Idrisi, 
versão Selva 17.0 (LABS, 2012). A comparação para quantificação foi realizada com as probabilidades de mudança de uma classe para outra, em um instante estimado (2046), referente ao intervalo de trinta anos, através das Cadeias de Markov, cujas probabilidades de transição são derivadas de amostras relativas ao instante de tempo atual (2011 e 2016). A seleção desses instantes é fundamental, pois ela vai definir os futuros, a partir da amostra apresentada. Através da alteração observada no tempo " $\mathrm{t}$ " e no tempo " $\mathrm{t}+1$ " fazse a predição para o futuro (SOARES-FILHO, 1998; MANSILLA BACA et al. 2007; RUHOFF et al., 2010; BESER DE DEUS, 2013).

O modelo de deteç̧ão de mudança entre as classes "Floresta" e "Não Floresta" foi demonstrado pela Figura 6. O resultado dessa consulta gerou um modelo que espacializou as mudanças. E, finalmente, para a simulação futura, levando em consideração a transição "Floresta para Não Floresta" na MBRF, foi utilizada a técnica de predição markoviana, sistema probabilístico que evolui em determinado período de tempo presente para o âmbito de um cenário futuro tendencial.

A matriz de transição é uma modelagem empírica de sistemas que descreve a mesma como um processo estocástico (em teorias de probabilidade). Baseada em Markov, ela é uma matriz quadrada MxM, estocástica, em que os elementos representam a probabilidade de mudança de um tema para outro. A MT compreende uma representação matemática das cadeias de Markov (MARKOV, 1971, p. 45; HARVEY, 1974; HAYKIN, 2001; BRIASSOULIS, 2000; MANSILLA BACA, 2002; MANSILLA BACA et al., 2007; PEDROSA e CÂMARA, 2007; CONSTANTINOU, 2007; RUHOFF et al., 2010; GRIGOLETTI, 2012).

A modelagem gerou uma matriz de transição com probabilidades de mudanças entre as classes, em um instante estimado (2046), através das Cadeias de Markov, cujas probabilidades de transição são derivadas de amostras relativas ao instante de tempo T1 e T2 (SOARES-FILHO et al., 1998; MANSILLA BACA et al., 2007; RUHOFF et al., 2010; BESER DE DEUS, 2013) que serviu como base para a quantificação das classes futuras e auxiliou na análise comparativa presente-futuro.

\section{RESULTADOS E DISCUSSÃO}

\section{Cobertura da terra na Microbacia do Rio Fagundes em 2011}

Após as análises serem elaboradas, observou-se a cobertura da terra em 2011 na MBRF. A Figura 2 e a Tabela 3 mostram em classes, a área ocupada em hectare e o percentual de cobertura da terra. A classe de cobertura da terra "Floresta" cobria 52\%, 1.547,19 hectares, e a classe "Não Floresta", 47,47\% ou 1.412,75 hectares (Tabela 1). A "Floresta" é 4,53\% maior que a "Não Floresta". Neste cenário, a cobertura "Floresta", em termos de extensão e quantidade, cobria a maior parte da microbacia. 
Figura 3. Mapas de cobertura da terra da Microbacia do Rio Fagundes em 2011 e em 2016

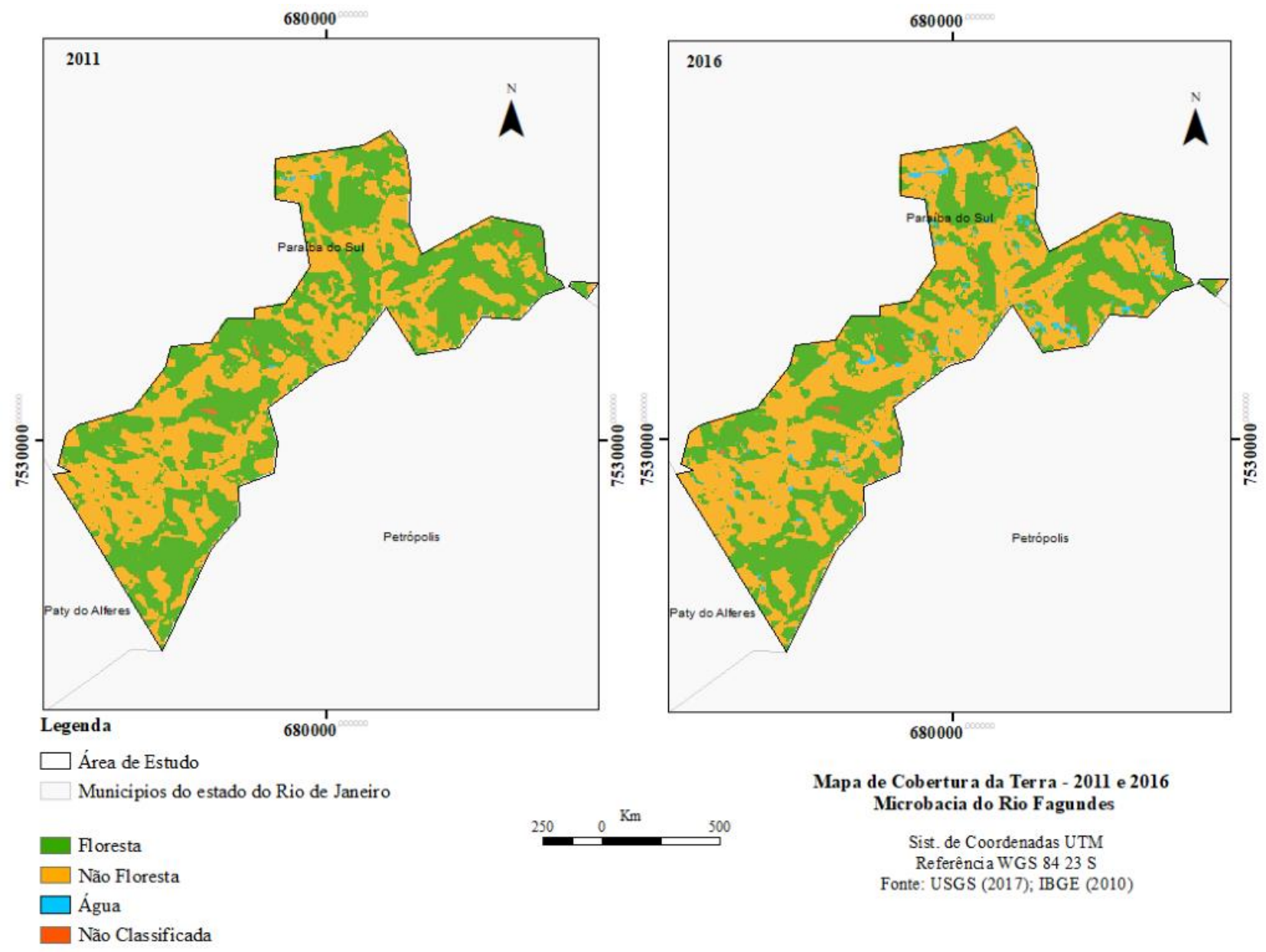

Tabela 3. Cobertura da terra na Microbacia do Rio Fagundes, ano 2011

\begin{tabular}{lll}
\hline Classe & Área (ha) & Percentual (\%) \\
\hline Floresta & $1.547,19$ & 52 \\
Não Floresta & $1.412,75$ & 47,47 \\
Água & 3,94 & 0,13 \\
Não classificada & 11,84 & 0,40 \\
Total & $2.975,72$ & 100 \\
\hline
\end{tabular}

De maneira similar a 2011, foi realizada a análise da cobertura da terra em 2016. A Figura 4 e a Tabela 4 mostram a classe, a área ocupada em hectare e o percentual de cobertura da terra em ambiente Idrisi Selva (2014). A classe de cobertura da terra "Floresta" cobria 44,6\%, 1.327,45 hectares, e a classe "Não Floresta", 52,8 \% ou 1.573,15 hectares (Tabela 4) o que evidencia uma cobertura "Não Floresta" maior que "Floresta" em 8,2\%. Em 2016, a cobertura "Não Floresta", em termos de extensão e quantidade, cobria a maior parte da microbacia. 
Tabela 4. Cobertura da terra na Microbacia do Rio Fagundes, ano 2016

\begin{tabular}{ccc}
\hline Classe & Área (ha) & Percentual (\%) \\
\hline Floresta & $1.327,45$ & 44,6 \\
Não Floresta & $1.573,15$ & 52,8 \\
Água & 58,07 & 1,95 \\
Não classificada & 17,05 & 0,56 \\
Total & $2.975,72$ & 100 \\
\hline
\end{tabular}

\section{Cenário de mudanças na cobertura da terra na transição 2011-2016 na Microbacia do Rio Fagundes}

Quanto às mudanças na cobertura da terra entre 2011 e 2016 na MBRF, observa-se, na Figuras 4 e 5, os ganhos e perdas entre as classes da cobertura da terra. Há um aumento da cobertura "Não Floresta" e um aumento da "Água", este último devido ao incentivo da cultura da piscicultura, além de um ligeiro aumento da classe "Não classificada" devido ao uso de diferentes sensores e imageamento. Também pode ser observada uma significativa diminuição da "Floresta".

Figura 4. Ganhos e perdas na cobertura da terra entre 2011 e 2016 na MBRF

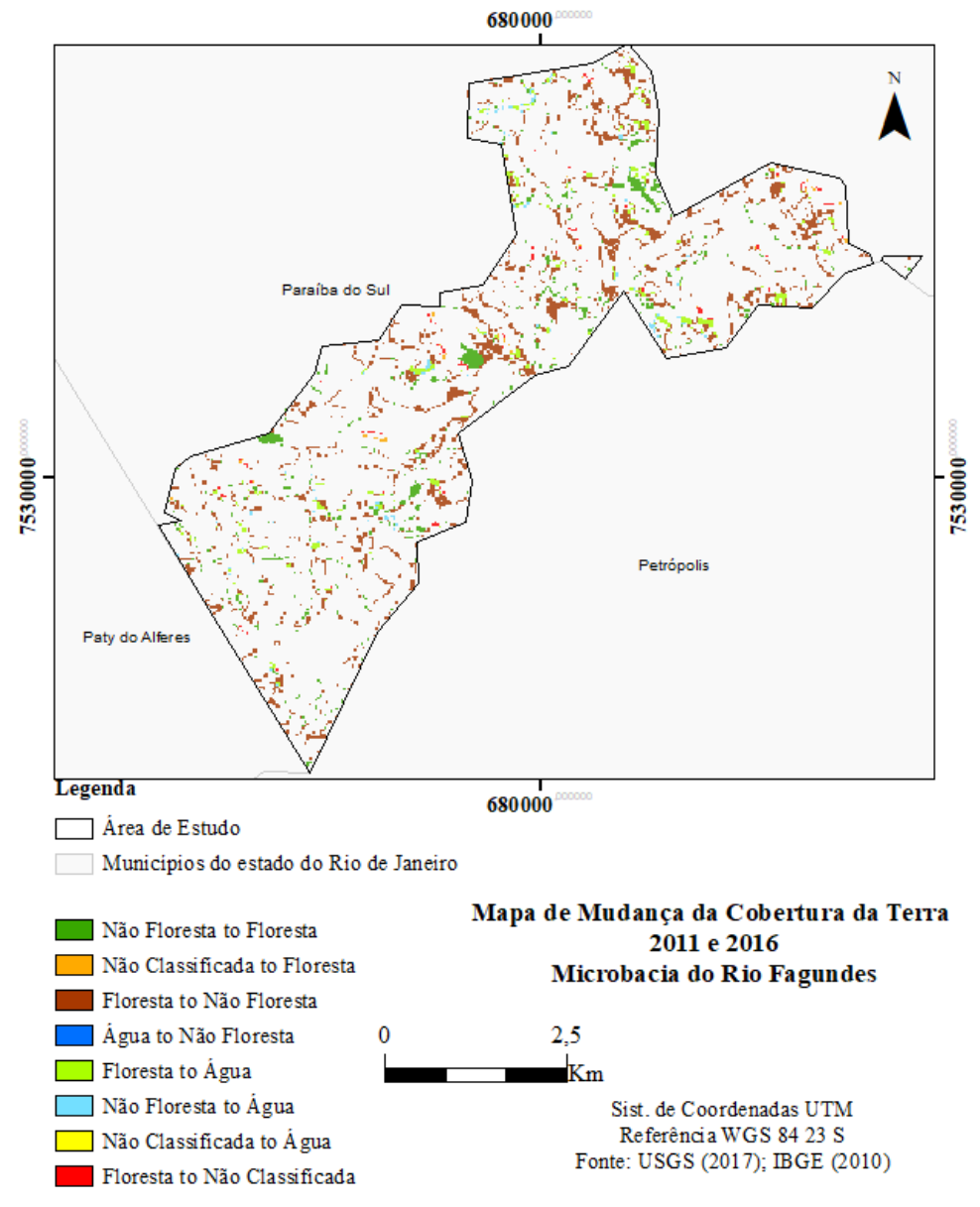

Legenda (extra) Espacialização de ganhos e de perdas de uma classe em favor de outra classe na MBRF. 
Figura 5. Ganhos e perdas entre as classes de cobertura da terra entre 2011 e 2016

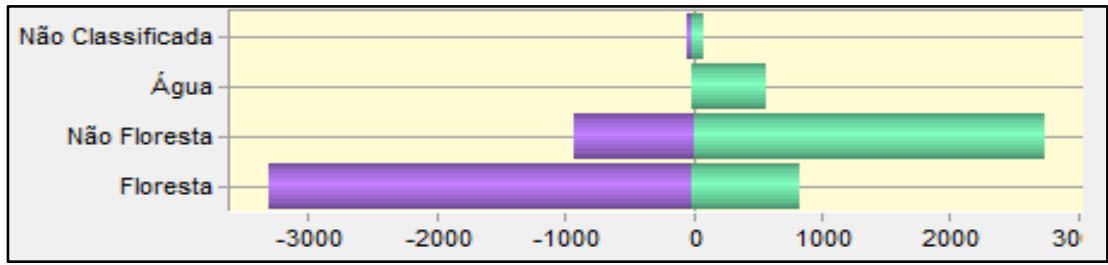

Legenda: Representação do ganho (em verde) e das perdas (em roxo) da cobertura da terra em hectares entre 2011 e 2016

Comparando somente a porcentagem de perda de "Floresta" para "Não Floresta", de 2011 para 2016, a classe "Floresta" diminuiu 7,4\%, enquanto a classe “Não Floresta" aumentou 5,33\% (Tabela 3 e Tabela 4).

Na Figura 6, o processo de retração da floresta é espacializado através do mapa de transição "Floresta para Não Floresta" entre 2011 e 2016. Em vermelho são as áreas que se tornaram “Não Floresta”. Na Figura 7, a tendência cúbica de propagação espacial de mudança indica a direção para a qual a mudança de cobertura da terra está se dirigindo; neste caso, a mudança de "Floresta" para "Não Floresta" demonstra uma concentração no interior/centro da área de estudo, irradiando-se em direção às bordas da microbacia (MBRF). As mudanças de "Floresta" para "Não Floresta" se concentram, mais significativamente, na porção norte/nordeste, indo no sentido de uma força direcionadora e perdendo força em direção à porção sul/sudoeste, fazendo limite com outra bacia em Paty do Alferes, de uso do solo e cobertura da terra semelhante à Microbacia Rio do Fagundes.

Figura 6. Transição de “Floresta para Não Floresta” entre 2011 e 2016 na Microbacia do Rio Fagundes

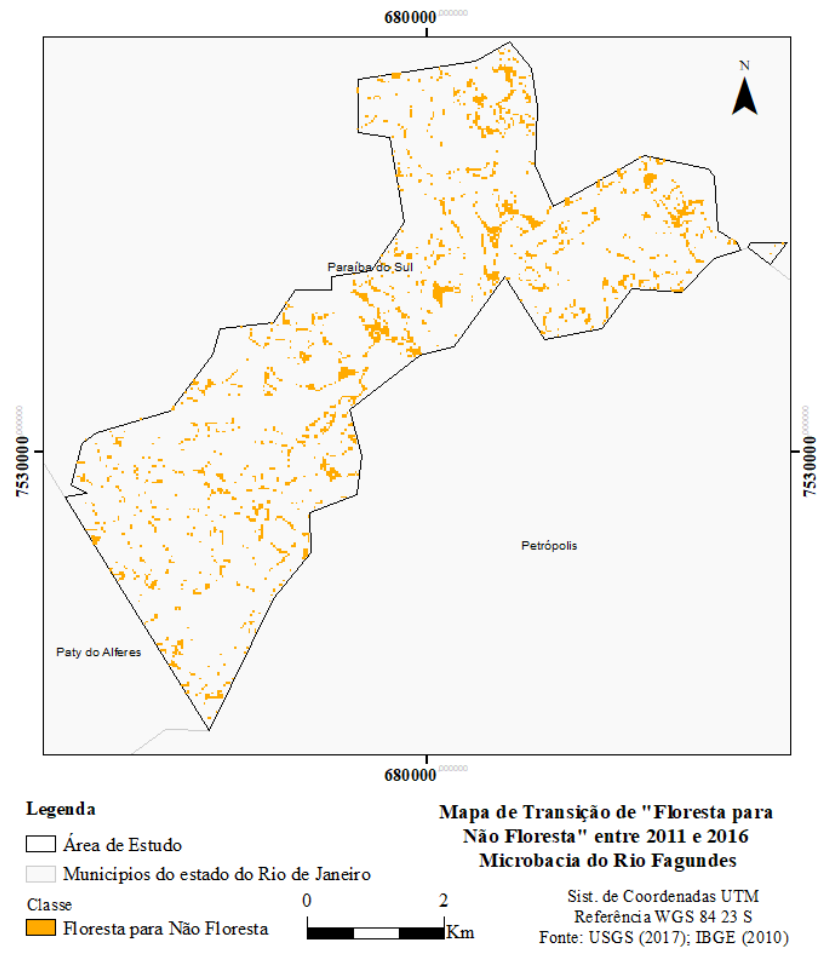

Legenda (extra) No mapa, a cor laranja demonstra a transição do que era “Floresta” em 2011 e se tornou “Não Floresta” em 2016. 
Figura 7. Mapa de tendência cúbica “Floresta” para “Não Floresta”

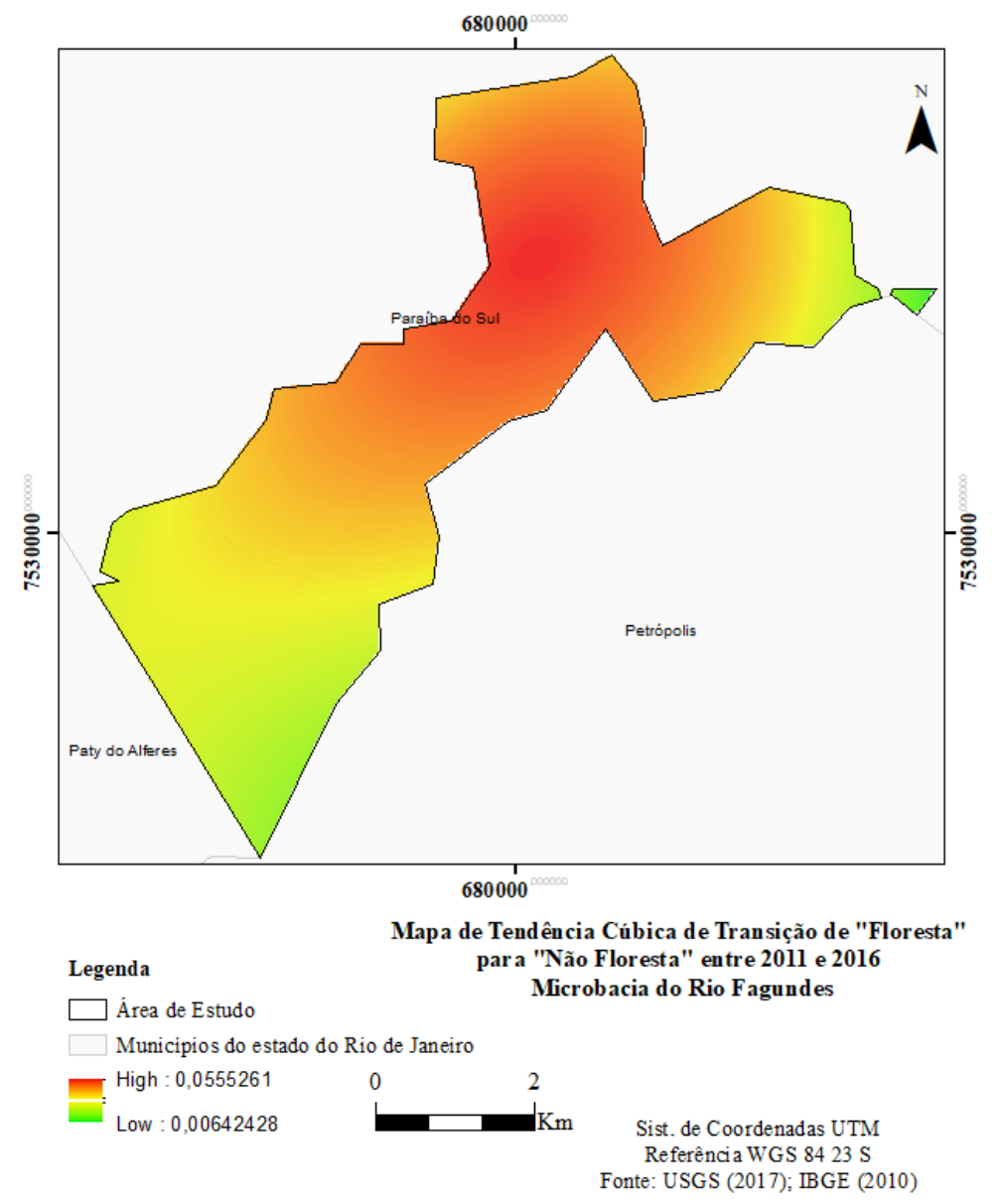

Legenda (extra): A cor laranja demonstra que a tendência cúbica de propagação de "Floresta" para "Não Floresta" se inicia no interior/centro da área de estudo se propaga em direção às bordas (amarelo e verde).

A partir da análise comparativa entre os dois períodos (2011-2016), é possível afirmar que houve um avanço do desmatamento para todas as categorias de APPs (artigo 4으. incisos I a XI; BRASIL, 2012, s/p), incluindo as APPs de entorno de nascentes. A classe "Floresta" foi visivelmente reduzida em favor da classe "Não Floresta".

A Figura 8 demonstra o mapa de transição "Floresta para Não Floresta" e "Não Floresta para Floresta" (entre 2011 e 2016). Nela é possível visualizar, em vermelho, que fragmentos da "Floresta" foram desmatados, transformando-se em "Não Floresta". Ainda é possível visualizar, em amarelo, que fragmentos se regeneraram, ou seja, que fragmentos da cobertura "Não Floresta" tornaram-se "Floresta". Claramente se visualizam mais fragmentos em vermelho que fragmentos em amarelo. Em campo é possível visualizar a transformação de "Floresta para Não Floresta" (Figura 9). 
Figura 8. Intercâmbio “Floresta” para “Não Floresta” e “Não Floresta” para “Floresta” (entre 2011 e 2016) na Microbacia do Rio Fagundes

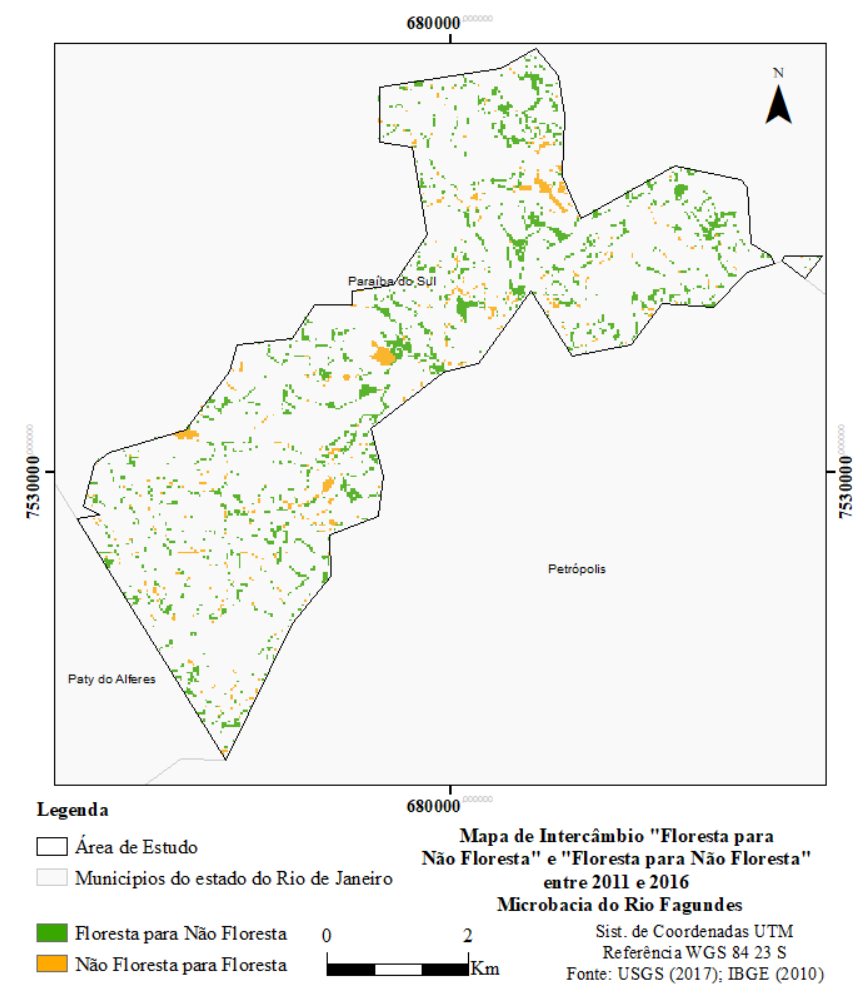

Legenda (extra): A cor laranja demonstra a transição do que era "Floresta" em 2011 e tornou-se "Não Floresta" em 2016. E a cor verde demonstra a transição do que era "Não Floresta" em 2011 e tornou-se "Floresta" em 2016.

Figura 9. Área onde houve transição da classe "Floresta" para "Não Floresta" na MBRF

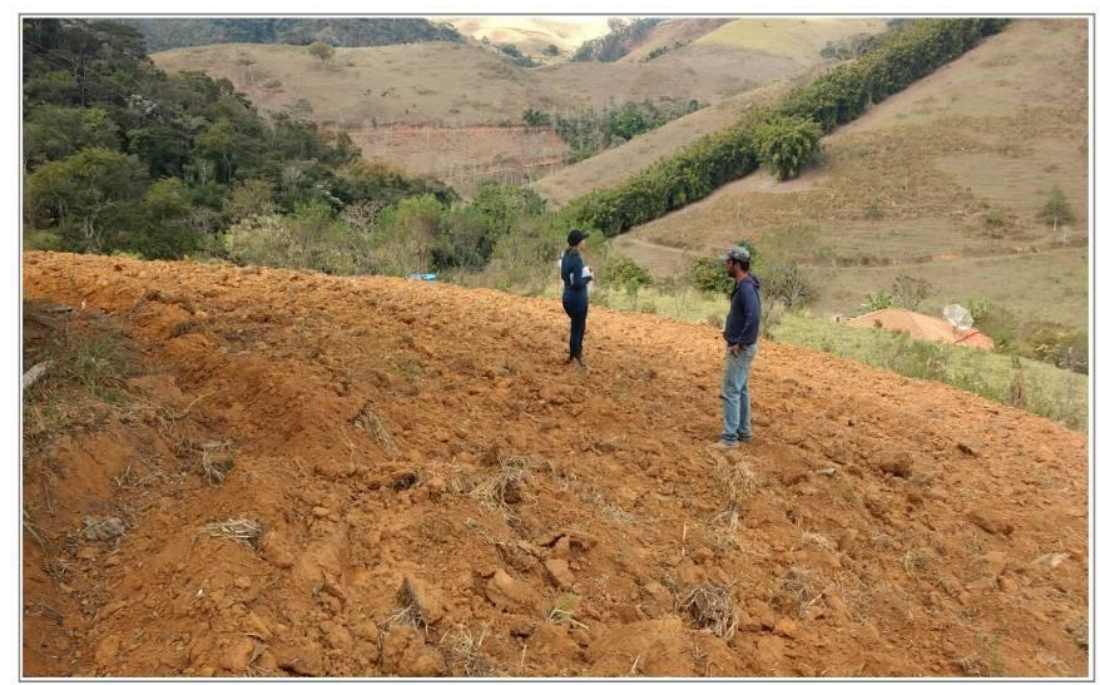

Legenda: Retirada da cobertura da terra "Floresta" para o desenvolvimento de atividade agrícola.

\section{Simulação do cenário futuro de cobertura da terra em 2046 na Microbacia do Rio Fagundes}

Para o cenário futuro tendencial de 2046, apresenta-se a predição markoviana na Tabela 5. Há a possibilidade de aumento da classe "Não Floresta", se combinada com a classe "Floresta", para 52,45\%. Dadas 
outras classes, por exemplo, "Não Floresta" combinada com a própria "Não Floresta", 77,64\%. Ou seja, há um cenário pessimista de não recuperação da "Floresta" e de manutenção da classe "Não Floresta". O mesmo ocorre com "Água", existe maior probabilidade de se manter o cenário e menor probabilidade de mudança.

Tabela 5. Predição markoviana para o ano de 2046

\begin{tabular}{lllll}
\hline & \multicolumn{4}{l}{ Probabilidade (em porcentagem \%) de mudança para } \\
Dadas as classes & Floresta & Não Floresta & Água & Não Classificada \\
\hline Floresta & 35,64 & 52,45 & 11,12 & 0,79 \\
Não Floresta & 16,85 & 77,64 & 5,31 & 0,20 \\
Água & 1,17 & 10,90 & 87,91 & 0,01 \\
Não Classificada & 47,61 & 36,44 & 8,92 & 7,02 \\
\hline
\end{tabular}

\section{CONCLUSÃO}

O módulo LCM disponível no Idrisi Selva possibilitou os cruzamentos de dados necessários para identificar e mapear as transformações ocorridas na área de estudo. Os mapas de cobertura da terra foram utilizados para uma comparação da análise de mudanças nas quatro classes analisadas entre 2011 e 2016.

A análise mostrou uma diminuição de "Floresta" e um aumento para "Não Floresta". O aumento da classe "Não Floresta" entre 2011 e 2016 demonstra o comprometimento das florestas e, consequentemente, das áreas de preservação permanente, bem como a quantidade de água produzida pelas chamadas áreas verdes. Entretanto, o aumento da classe "Água" foi substancialmente maior no período proposto. A partir de uma pesquisa de campo em entrevista com a Emater (2016), foi possível perceber que a concentração de água em locais estratégicos se deve ao incentivo à criação de peixes na microbacia, da parte do estado do Rio de Janeiro, à piscicultura, bem como ao incentivo a políticas territoriais de desenvolvimento agrícola.

Desta forma, a apresentação e espacialização dos dados na Microbacia do Rio Fagundes com a análise temporal utilizada possibilitaram um maior entendimento das pressões ambientais sobre as Áreas de Preservação Permanente, ou seja, considerada aqui principalmente sobre a classe "Floresta".

A predição markoviana para 2046 prevê a continuidade da diminuição de "Floresta" com aumentos sensíveis de áreas de "Não Floresta". Essa tendência é em função da continuidade das condições ambientais que atualmente se apresentam em relação às APPs e seus usos.

Com base nos dados avaliados e nos mapas apresentados, há uma predição de um futuro tendencial pessimista, no qual maiores esforços têm de ser empregados no sentido de uma preservação da "Floresta" para que em 2046 não haja maiores perdas, ou seja, não ocorra a concretização deste cenário de desmatamento e a classe "Floresta" não se recupere. As mudanças e tendências ambientais previstas podem interferir nas APPs e, por consequência, na dinâmica da microbacia. 
Recomenda-se a intensificação do monitoramento da MBRF, dos investimentos e dos recursos empregados para desenvolvimento rural sustentável e recuperação das nascentes, como também novos estudos relacionados ao assunto.

Assim, para este artigo, o uso das imagens dos sensores Landsat nos períodos secos dos anos selecionados com a utilização da ferramenta LCM/Idrisi, mostrou-se uma potencial ferramenta para a espacialização de cenários ambientais, tanto dos chamados cenários atuais como da predição futura tendencial.

\section{REFERÊNCIAS}

BATISTELLA, M.; ALVES, D. E.; MORAN, E. (org.) Amazônia: Natureza e Sociedade em Transformação. São Paulo: Editora UNESP, 2008. 304p.

BESER DE DEUS, L. A. Espaço e Tempo como Subsídios à Construção de Cenários de Uso e Cobertura da Terra para o Planejamento Ambiental na Amazônia: O Caso da Bacia do Rio Acre. 2013. 384p. Tese (Doutorado em Planejamento Energético) - Universidade Federal do Rio de Janeiro/COPPE, Rio de Janeiro, 2013.

BRASIL. Lei 12.651, de 25 de maio de 2012. Código Florestal Brasileiro. 2012. Disponível em: http://www.planalto.gov.br/ccivil_03/_Ato2011-2014/2012/Lei/L12651.htm Acesso em: 20 nov. 2016

BRASIL. Projeto de Lei 1876/1999 do "Novo Código Florestal Brasileiro". 1999. Disponível em: http://camara.gov.br/proposicoesWeb/tramitação Acesso em: 20 nov. 2016

CANDIDO, M. Z.; CALIJURI, M. L.; MOREIRA NETO, R. F. Modelagem do Uso, Ocupação e Desenvolvimento de uma Região com a Ferramenta Land Change Modeler (LCM) e Imagens Orbitais. In: CONGRESSO BRASILEIRO DE

CARTOGRAFIA, 24., 2010, Aracaju. Anais... Aracaju: INPE, 2010. p. 663- 668. Disponível em: https://dsr.inpe.br/sbsr2013/files/p1219.pdf Acesso em: 22 nov. 2016.

CASTRO, P. S.; GOMES, M. A. Técnicas de conservação de nascentes. Ação Ambiental, Viçosa, v. 20, n. 4, p. 24-26. 2001.

CHENG, S.; DING, N. Land Change Modeler Application: Summer Internship with Clark Labs. Bélgica: Editora International Development, Community and Environment (IDCE), 2016, p. 57.

ONGALTON, R. G. A. Review of Assessing the Acuracy of Classification Remotely Sensed Data. Remote Sensing of Environment, v. 37 , n. 1, p. 35-46. 1991.

CONSTANTINOU, E. Dinâmica Intra-Urbana: Aleatoriedade e Emergência de Padrões Espaço-Temporais. Cadeias de Markov. 2007. 247p. Dissertação (Mestrado em Planejamento Urbano e Regional) - Universidade Federal do Rio Grande do Sul, 2007.

COPPETEC. Plano de Recursos Hídricos da Bacia do Rio Paraíba do Sul. Rio de Janeiro: Diagnóstico dos Recursos Hídricos, Laboratório de Hidrologia e Estudos do Ambiente, Universidade Federal do Rio de Janeiro/COPPE, 2006. 201p.

DANTAS, M. E. Diagnóstico Geoambiental do Estado do Rio de Janeiro. Rio de Janeiro: Serviço Geológico do Brasil/CPRM. Portal do Governo do Estado do Rio de Janeiro, 2000. Disponível em:

http://rigeo.cprm.gov.br/jspui/bitstream/doc/17229/14/rel_proj_rj_geoambiental.pdf Acesso em: 07 nov. 2017.

EMATER. Empresa Estadual de Assistência Técnica e Extensão Rural do Estado do Rio de Janeiro (Sede Paraíba do Sul). 2016. Disponível em: http://www.emater.rj.gov.br/ Acesso em: 08 dez. 2016

ESRI. ArcGIS.10.3 for Desktop. Versão 10.3. 2014. Programa de Computador. Disponível em: https://www.esri.com/pt-br/home Acesso em: 20 nov. 2016.

FONSECA, L. M. G. Processamento digital de imagens: Apostila da disciplina de Processamento digital de imagens dada no curso de pós-graduação em sensoriamento remoto do Instituto Nacional de Pesquisas Espaciais / Divisão de Processamento de Imagens São José dos Campos: Instituto Nacional de Ciências Espaciais, 2000. Disponível em:

http://www.dpi.inpe.br/ /eila/ser437/PDI_7_seg_clas.pdf Acesso em: 23 nov. 2016.. 
GARAY, I.; BECKER, B. (org.). As dimensões humanas da biodiversidade. O desafio de novas relações sociedade-natureza no século XXI. Petrópolis: Vozes, 2006. 484p.

GRIGOLETTI, P. S. Cadeias de Markov. 2012. 123p. Dissertação (Mestrado em Ciência da Informação) - Universidade Católica de Pelotas, Rio Grande do Sul, 2012. Disponível em:

https://www.researchgate.net/publication/228747669_Cadeias_de_Markov/link/Odeec5344683f96036000000/download Acesso em: 20 nov. 2016.

JARDIM, M. H. Pagamentos por Serviços Ambientais na Gestão de Recursos Hídricos: O caso de Extrema - MG. 2010. 195p. Dissertação (Mestrado em Desenvolvimento Sustentável) - Universidade de Brasília, Brasília, 2010.

KHAWALDAH, H. A. A Prediction of Future Land Use/Land Cover in Amman Area Using GIS Based Markov Model and Remote Sensing. Journal of Geographic Information System, v. 8, p. 412-427, 2016.

LABS, C. The Land Change Modeler for Ecology Sustainability. Idrisi Selva:

Guide to GIS and Image Processing. Massachusetts: Clark University, 2012.

LEITE, E. F.; ROSA, R. Análise do uso, ocupação e cobertura da terra na bacia hidrográfica do Rio Formiga, Tocantins. Observatorium: Revista Eletrônica de Geografia, v. 12, n. 4, p. 90-106, 2012.

LUIZ, C. H. P. Modelagem da cobertura da terra e análise da influência do reflorestamento na transformação da paisagem: Bacia do Rio Piracicaba e Região Metropolitana do Vale do Aço. 2014. 141p. Dissertação (Mestrado em Análise e Modelagem de Sistemas Ambientais) - Universidade Federal de Minas Gerais, Belo Horizonte, 2014.

MANSILLA BACA, J. F. M. Dinâmica da Paisagem: métodos analíticos, modelos de classificação e simulação prognóstica, sob a ótica geoecológica. 2002. 184p. Tese (Doutorado em Geografia) - Universidade Federal do Rio de Janeiro, Rio de Janeiro, 2002.

MANSILLA BACA, J. F. M.; COELHO NeTto, A. L; MENEZES, P. M. L. Modelagem da Dinâmica da Paisagem com Processos de Markov. In: MEIRELLES, M. S. P.; CÂMARA, G.: ALMEIDA, C. M. Geomática: modelos e aplicações ambientais. Brasília: Embrapa Informação Tecnológica, 2007. 592p.

MARKOV, A. A. Extension of the limit theorems of probability theory to a sum of variables connected in a chain. In: HOWARD, R. A. Dynamic Probabilistic Systems, v. 1, n. 1, p. 329-350, 1971 (Series Markov Chains).

MISHRA, V. N.; RAI, P. K.; MOHAN, K. Prediction of land use changes based on land change modeler (LCM) using remote sensing: a case study of Muzaffarpur (Bihar), Índia. Journal of the Geographical Institute Jovan Cvijic, v. 64, p. 111-127, 2014.

NOVO, E. M. L. Sensoriamento Remoto: Princípios e aplicações. São Paulo: Blucher, 2010. 387p.

PAGIOLA, S; VON GLEHN, H. C.; TAFFARELLO, D. Experiências de Pagamentos por Serviços Ambientais no Brasil. São Paulo: Secretaria Municipal do Ambiente, 2013. 336p.

PEDROSA, B. M.; CÂMARA, G. Modelagem Dinâmica e Sistemas de Informações Geográficas. In: MEIRELLES, M. S. P.; CAMARA, G.; ALMEIDA, C. M. de. (org.). Geomática: Modelos e Aplicações Ambientais. Brasília: Embrapa Informação Tecnológica, 2007, p. 237280.

RODRIGUES, R. R.; DE FREITAS LEITÃO FILHO, H. Matas ciliares: conservação e recuperação. São Paulo: Editora da Universidade de São Paulo, 2000. 320p.

RUHOFF, A.; FANTIN-CRUZ, I.; COLLISCHONN, W. Modelos de simulação dinâmica do desmatamento na Amazônia. Caminhos de Geografia, v. 36, n. 11, p. 258-268, 2010.

SANTOS, R. F. dos. Planejamento Ambiental: teoria e prática. São Paulo: Oficina de Texto, 2004. 184p.

SÃO PAULO. Secretaria do Meio Ambiente/Coordenadoria de Planejamento Ambiental. Projeto Ambiental Estratégico Cenário Ambiental 2020. São Paulo: SMA/CPLA, 2009. 150p.

SARTORI, A. A.; POLONIO, V. D.; ARGENTIN, R. N.; ZIMBACK, C. R. L. (2013) Modelagem da dinâmica do uso e ocupação do solo na sub-bacia hidrográfica do Rio Novo - SP: Land Change Modeler - LCM. In: Simpósio Brasileiro de Sensoriamento Remoto - SBSR, 16. , 2013, Foz do Iguaçu. Anais... Foz do Iguaçu: INPE, 2013. p. 663-673. 
SEAPEC. Secretaria do Estado de Agricultura, Pecuária e Abastecimento. Rio de Janeiro: Governo do Estado do Rio de Janeiro, 2016. Disponível em: http://www.rj.gov.br/secretaria/Default.aspx?sec=AGRICULTURA Acesso em: 21 nov. 2016.

SOARES FILHO, B.; ALENCAR, A.; NEPSTAD, D.; CERQUEIRA, G. C.; VERA DIAZ, M.; RIVERO, S.; SOlÓRZANO, L.; VOLL, E. Simulating the Response of Land-Cover Changes to Road Paving and Governance Along a Major Amazon Highway: The Santarém-Cuiabá Corridor. Global Change Biology, v. 7, n. 10, p. 745-764, 2004.

SOARES FILHO, B. S.; CERQUEIRA, G. C. Projeto Dinâmica. 2005. Disponível em: https://csr.ufmg.br/dinamica/ Acesso em: 20 nov. 2016.

SOARES FILHO, B. S.; GARCIA, R. A.; RODRIGUES, H.; MORO, S.; NEPSTAD, D. Nexos entre as dimensões socioeconômicas e o desmatamento: A caminho de um modelo integrado. In: BATISTELLA, M.; ALVES, D.; MORAN, E. (org.). Amazônia. Natureza e Sociedade em Transformação. São Paulo: Edusp, 2008. p. 181-217.

SOARES FILHO, B.; NEPSTAD, D.; CURRAN, L.; CERQUEIRA, G. C. Conservation Scenarios for the Amazon. Nature, v. 7, n. 10, p. 520523, 2005.

USGS. Science for changing world. Image Catalog, 2016. Disponível em: https://www.usgs.gov/ Acesso em: 20 dez. 2016. 